\title{
QUALIDADE FÍSICA DE UM LATOSSOLO VERMELHO CULTIVADO COM SOJA SUBMETIDO A NÍVEIS DE COMPACTAÇÃO E DE IRRIGAÇÃO(1)
}

\author{
Paula Regina de Oliveira( ${ }^{(2)}$, José Frederico Centurion ${ }^{(3)}$, Maria \\ Aparecida Pessôa da Cruz Centurion(4), Helena Baroni Junqueira \\ Franco $^{(5)}$, Fabiana de Souza Pereira ${ }^{(6)}$, Laerte Souza Bárbaro Júnior ${ }^{(7)}$ \\ \& Karina de Vares Rossetti ${ }^{(8)}$
}

\begin{abstract}
RESUMO
Manter uma boa qualidade física do solo é importante para preservar o meio ambiente, além de maximizar a produtividade das plantas. Um solo compactado poderá interferir na densidade, na porosidade e na resistência do solo à penetração, influenciando no crescimento radicular. A presente pesquisa objetivou avaliar a qualidade física de um Latossolo Vermelho eutroférrico, textura argilosa, com a cultivar de soja $\mathrm{CAC}-1$, submetido a quatro níveis de compactação e três níveis de irrigação, utilizando os atributos físicos do solo, assim como a correlação do sistema radicular com a produtividade da cultura. $\mathrm{O}$ delineamento experimental foi em blocos ao acaso, com parcelas subdivididas, com quatro repetições. Os níveis de compactação foram: $C_{0}=0, C_{2}=2, C_{4}=4 \mathrm{e}$ $\mathrm{C}_{6}=6$ passadas, no mesmo local, de um trator de $11 \mathrm{t}$. Foram coletadas amostras indeformadas de solo nas entrelinhas da cultura da soja, para determinação dos atributos físicos, nas camadas de $0-0,10$ e $0,10-0,20 \mathrm{~m}$. A produtividade máxima da soja foi obtida com a resistência do solo à penetração de $0,71 \mathrm{MPa}$. $\mathrm{O}$ sistema radicular correlacionou-se inversamente com a produtividade da soja.
\end{abstract}

Termos de indexação: produtividade, sistema radicular, resistência do solo à penetração.

(1) Received for publication in Juny 28, 2011 and approved in November 20, 2011.

(2) Doutoranda do Programa de Pós-Graduação em Produção Vegetal, Departamento de Solos e Adubos da Faculdade de Ciências Agrárias e Veterinárias, Universidade Estadual Paulista - FCAV/UNESP. Via de Acesso Professor Paulo Donato Castellane s/n, CEP 14884-900 Jaboticabal (SP). Bolsista da FAPESP. E-mail: paularoliveira@yahoo.com.br

(3) Professor Adjunto do Departamento de Solos e Adubos da Faculdade de Ciências Agrárias e Veterinárias, Universidade Estadual Paulista - FCAV/UNESP. Bolsista CNPq. E-mail: jfcentur@fcav.unesp.br

(4) Professora do Departamento de Produção Vegetal da Faculdade de Ciências Agrárias e Veterinárias, Universidade Estadual Paulista - FCAV/UNESP. E-mail: cidinha@fcav.unesp.br

(5) Doutora do Programa de Pós-Graduação em Produção Vegetal da Faculdade de Ciências Agrárias e Veterinárias, Universidade Estadual Paulista - FCAV/UNESP. E-mail: hbj_franco@yahoo.com.br

(6) Doutoranda do Programa de Pós-Graduação em Ciência do Solo, Departamento de Solos e Adubos da Faculdade de Ciências Agrárias e Veterinárias, Universidade Estadual Paulista - FCAV/UNESP. E-mail: fabianadsp@hotmail.com

(7) Doutorando do Programa de Pós-Graduação em Produção Vegetal, Departamento de Produção Vegetal da Faculdade de Ciências Agrárias e Veterinárias, Universidade Estadual Paulista - FCAV/UNESP. E-mail: barbaro2303@hotmail.com

(8) Doutoranda do Programa de Pós-Graduação em Produção Vegetal, Departamento de Solos e Adubos da Faculdade de Ciências Agrárias e Veterinárias, Universidade Estadual Paulista - FCAV/UNESP. E-mail: krossetti@bol.com.br 


\title{
SUMMARY: PHYSICAL QUALITY OF AN OXISOL UNDER SOYBEAN AT DIFFERENT COMPACTION AND IRRIGATION LEVELS
}

\begin{abstract}
The maintenance of a good soil physical quality is essential to preserve the environment and maximize crop yields. A compacted soil can affect soil density, porosity and penetration resistance, influencing root growth. The purpose of this study was to evaluate the physical quality of an Oxisol, clay texture, with the soybean cultivar CAC-1, at four compaction and three irrigation levels, using the soil physical properties, as well as the relationship of root system with the crop yield. The experiment had a randomized block design, with split plots and four replications. The compaction levels were: $C_{0}=0, C_{2}=2, C_{4}=4, C_{6}=6$ passes of a tractor weighing 11 tons, at the same place. Undisturbed soil was sampled between the soybean rows, to determine the physical properties (layers $0-0.10$ and $0.10-0.20 \mathrm{~m}$ ). Soybean yields were highest at a soil penetration resistance of $0.71 \mathrm{Mpa}$. Root growth was inhibited by increased soil compaction.
\end{abstract}

Index terms: yield, root system, soil resistance.

\section{INTRODUÇÃO}

A cada ano a soja brasileira amplia sua participação no comércio internacional da oleaginosa. O Brasil deverá exportar mais de 30 milhões de toneladas, sendo mais de 21 milhões (68\%) para a China, superando o ano agrícola 2009/10, cuja exportação foi de $65 \%$. Estima-se que a cultura ocupe uma área de aproximadamente 24 milhões de hectares - cifra ligeiramente superior à da safra passada (Agrianual, 2011).

Manter uma boa qualidade física do solo é imprescindível para o sucesso no cultivo das culturas, a fim de maximizar a produtividade e manter a sustentabilidade. No entanto, o solo, por ser o suporte da produção agrícola, sofre alterações significativas em seus atributos físicos como consequência do tráfego excessivo realizado indiscriminadamente sob variadas condições de umidade do solo, ocasionando a compactação.

A compactação é um processo decorrente das práticas agrícolas que ocasiona degradação dos solos; ela se expressa por uma alteração estrutural que causa reorganização das partículas dos agregados, promovendo, concomitantemente, aumento da densidade do solo e redução da porosidade total e da macroporosidade (Stone et al., 2002), que podem alterar a disponibilidade de nutrientes e água às raízes das plantas, assim como reduzir a penetração de raízes além de aumentar a erosão e a energia necessária para o preparo do solo. Em consequência, há alteração no funcionamento bioquímico da planta, restringindo, entre outros fatores, o crescimento da parte aérea (Turner, 1997) e a produção da cultura. Para Kiehl (1979), a porosidade do solo é fundamental para a produção das culturas, estando a porosidade total próxima a $0,50 \mathrm{~m}^{3} \mathrm{~m}^{-3}$, sendo $34 \%$ para macroporos e $66 \%$ para microporos.
Vários atributos físicos do solo são utilizados para avaliar seu grau de compactação, entre os quais se destacam a densidade, a porosidade do solo e a resistência do solo à penetração. $\mathrm{A}$ densidade $(\mathrm{Ds})$ tem sido um atributo muito utilizado, por ser uma medida quantitativa com razoável sensibilidade e de fácil determinação (Camargo \& Alleoni, 1997). Entretanto, de acordo com Silva et al. (2006), a densidade do solo compactado, capaz de inibir o crescimento das plantas, varia conforme a classe de solo, a espécie plantada e as condições de umidade do solo. Assim, para um mesmo valor de Ds, um solo argiloso pode estar muito compactado, enquanto para outro tipo de solo com textura mais arenosa esse valor pode indicar solo solto (Beutler et al., 2008).

A resistência do solo à penetração $(\mathrm{RP})$ tem sido mais frequentemente utilizada para avaliar a compactação do solo, por apresentar melhores correlações e ter relações diretas com o crescimento radicular e com a produtividade das plantas (Letey, 1985).

Varquez et al. (1989), analisando sistemas de manejo e compactação do solo, verificaram que a resistência do solo à penetração de 1,57 a 1,59 $\mathrm{MPa}$ (camada de 0,05-0,35 m) esteve associada com a produtividade máxima de soja, visto que ela decresce com o aumento da resistência do solo à penetração. Em Latossolo Vermelho argiloso, a produtividade de soja foi adequada até a resistência do solo à penetração de 1,80 MPa, segundo Silva et al. (2000). Conforme Dexter (1987), a compactação em solo seco é mais prejudicial, visto que pode haver crescimento radicular em condições de maior umidade do solo, com valores de resistência à penetração superiores a 4,0 MPa. Entretanto, para obter alta produtividade de soja, o valor crítico de resistência do solo à penetração varia com a cultivar e a classe de solo. 
Segundo Barber (1994), a produtividade de soja decresceu a partir da resistência do solo à penetração de 2,0 a 3,0 MPa, apresentando menores valores para anos com maior precipitação pluvial, em consequência de deficiência de aeração no solo compactado, além de menor drenagem interna. Conforme supracitado, a cultura da soja é sensível à compactação do solo pelo tráfego de máquinas.

Beutler \& Centurion (2004) mencionaram que a compactação pode impedir o crescimento de raízes e diminuir o volume de solo explorado pelo sistema radicular e, consequentemente, reduzir a altura de plantas. Isso diminui a taxa de uso de água pelas raízes, a qual apresenta correlação linear com o peso de matéria seca da parte aérea das plantas (Lipiec et al., 1993), visto que diminui a eficiência de absorção de nutrientes e a quantidade de $\mathrm{N}$ fixado pela leguminosa.

Nesse contexto, a presente pesquisa objetivou avaliar a qualidade física de um Latossolo Vermelho eutroférrico, para a cultura da soja, submetido a quatro níveis de compactação e três níveis de irrigação, utilizando atributos do solo tradicionais, como a densidade, a porosidade e a resistência do solo à penetração, assim como a correlação do sistema radicular com a produtividade da cultura.

\section{MATERIAL E MÉTODOS}

O experimento foi desenvolvido na área experimental da Fazenda de Ensino, Pesquisa e Produção da Universidade Estadual Paulista (UNESP/FCAV), Jaboticabal (SP), com coordenadas geográficas de $21^{\circ} 15^{\prime} 29^{\prime \prime}$ de latitude sul e $48^{\circ} 16^{\prime} 47^{\prime \prime}$ de longitude oeste de Greenwich, com altitude média de $600 \mathrm{~m}$. O clima da região, de acordo com a classificação climática de Köppen, é do tipo Cwa, com verão quente e inverno seco, precipitação pluvial média anual de $1.428 \mathrm{~mm}$ e temperatura média de $21^{\circ} \mathrm{C}$ (Centurion, 1998). O solo foi classificado como Latossolo Vermelho eutroférrico típico, textura argilosa, A moderado, caulinítico-oxídico (LVef) (Andrioli \& Centurion, 1999).

A composição granulométrica do solo foi determinada, na camada de $0-0,20 \mathrm{~m}$, por meio da dispersão com $\mathrm{NaOH}\left(0,1 \mathrm{~mol} \mathrm{~L}^{-1}\right)$ e agitação lenta, durante $16 \mathrm{~h}$, sendo o teor de argila obtido pelo método da pipeta (Gee \& Bauder, 1986). Os resultados dessas análises estão apresentados no quadro 1.

$\mathrm{O}$ delineamento experimental foi em blocos ao acaso, com parcelas subdivididas, sendo cada unidade experimental constituída de quatro linhas de 4,0 m, espaçadas de 0,5 m. Foram consideradas como área útil as duas linhas centrais, desprezandose $0,5 \mathrm{~m}$ de cada extremidade, com quatro níveis de compactação $\left(\mathrm{C}_{0}=\right.$ solo não trafegado e $\mathrm{C}_{2}, \mathrm{C}_{4}$ e $\mathrm{C}_{6}$ corresponderam a 2,4 e 6 passadas de um trator de $11 \mathrm{t}$, respectivamente), três níveis de irrigação, cujas tensões utilizadas na determinação dos conteúdos de água foram de 0,001, 0,01 e 0,05 $\mathrm{MPa}$, e duas profundidades (0,0-0,1 e 0,1-0,2 m), com quatro repetições, perfazendo um total de 96 parcelas.

Antes da instalação do experimento, toda a área foi escarificada a cerca de $0,30 \mathrm{~m}$ de profundidade, seguida de aplicação de trifluralina e de uma gradagem niveladora. Logo após, a área foi irrigada por aspersão até próximo à capacidade de campo $(0,01 \mathrm{MPa})$, efetuando-se no dia seguinte a compactação. O trator (MF 620) trafegou por toda a parcela, no sentido do declive da área, de forma que os quatro pneus de mesma largura $(0,40 \mathrm{~m})$ e pressão interna comprimissem áreas paralelas entre si.

Em dezembro de 2009 foi semeada a cultivar de soja CAC-1, utilizando-se de uma semeadora-adubadora regulada para sulcar a área perpendicularmente à compactação, com espaçamento entrelinhas de $0,45 \mathrm{~m}$, e para distribuir $170 \mathrm{~kg} \mathrm{ha}^{-1}$ de adubo formulado 2-20-20, para obtenção da produtividade esperada de soja de 3,0 a $3,5 \mathrm{t} \mathrm{ha}^{-1}$, de acordo com a recomendação de Raij et al. (1996). Cerca de 30 dias após a emergência, realizou-se o desbaste de plantas para ajuste da população para 18 a 20 plantas $/ \mathrm{m}$. Após a semeadura a área foi irrigada, a fim de garantir a germinação e emergência das plântulas. Foram instalados tensiômetros na área experimental e, por meio de leituras diárias, procedeu-se à irrigação por sistema de aspersão.

A instalação desse ensaio ocorreu tardiamente, no mês de dezembro, devido às precipitações pluviais de 101,9 e 163,3 mm ocorridas nos meses de outubro e novembro de 2009, respectivamente, dificultando assim o uso de máquinas agrícolas para o preparo da área e, consequentemente, a semeadura.

Quadro 1. Análise química e física da amostra de solo da área experimental

\begin{tabular}{|c|c|c|c|c|c|c|c|c|c|c|c|c|c|}
\hline $\mathrm{pH} \mathrm{CaCl}_{2}$ & MO & $\mathrm{P}$ resina & $\mathbf{K}^{+}$ & $\mathrm{Ca}^{2+}$ & $\mathrm{Mg}^{2+}$ & $\mathbf{H}+\mathbf{A l}$ & SB & $\mathbf{T}$ & V & Argila & Silte & Areia fina & Areia grossa \\
\hline & $\mathrm{g} \mathrm{dm}^{-3}$ & $\mathrm{mg} \mathrm{dm}{ }^{-3}$ & 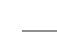 & 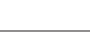 & $-\mathrm{mmol}$ & $\mathrm{dm}^{-3}$ & & & $\%$ & 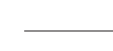 & 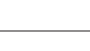 & $-\mathrm{g} \mathrm{kg}^{-1}$ & 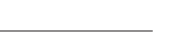 \\
\hline 5,3 & 23 & 56 & 4,6 & 38 & 16 & 28 & 58,6 & 86,6 & 68 & 550 & 240 & 110 & 100 \\
\hline
\end{tabular}


Trinta dias após a semeadura da soja foram coletadas 64 amostras indeformadas de solo, na entrelinha, com cilindros de $53,16 \times 10^{-6} \mathrm{~m}^{3}$ (0,03 $\mathrm{m}$ de altura e $0,048 \mathrm{~m}$ de diâmetro), para determinação dos atributos físicos: resistência do solo à penetração, densidade do solo e porosidade total, com oito repetições nas camadas de $0-0,10$ e $0,10-0,20 \mathrm{~m}$. Ainda nessas amostras, foram avaliadas a microporosidade do solo, por secagem (tensão de 0,006 MPa), em câmaras de pressão de Richards, com placa porosa (Klute, 1986); a porosidade total, segundo Danielson \& Sutherland (1986); e a macroporosidade, obtida pela diferença entre a porosidade total e a microporosidade.

As amostras foram saturadas por ascensão capilar em uma bandeja, durante $24 \mathrm{~h}$, e em seguida submetidas às tensões de 0,$001 ; 0,003 ; 0,006 ; 0,01$; 0,033; 0,06; 0,1; e 0,3 MPa em câmaras de Richards com placa porosa (Klute, 1986). Ao atingir o equilíbrio, na tensão de $0,01 \mathrm{MPa}$, as amostras foram pesadas para obtenção do peso saturado e submetidas à determinação da resistência do solo à penetração (RP), com duas subdeterminações por amostra. A RP foi determinada com o penetrômetro eletrônico estático de laboratório, com velocidade constante de penetração de $0,01 \mathrm{~m} \mathrm{~min}^{-1}$, registro de uma leitura por segundo, cone com semiângulo de $30^{\circ}$ e área de contato de $3,14 \times 10^{-6} \mathrm{~m}^{2}$, equipado com atuador linear e célula de carga de $20 \mathrm{kgf}$ acoplada a um microcomputador para a aquisição dos dados, conforme descrito por Tormena et al. (1998). Foram utilizadas 64 leituras, correspondentes ao centro geométrico de cada amostra, na profundidade de 1,0 a $2,0 \mathrm{~cm}$, obtendo-se cada leitura, as quais foram utilizadas para obtenção da resistência média à penetração em cada amostra, e calculado o valor das 128 leituras (duas subdeterminações por amostra) para representar a RP da amostra. Os resultados foram transformados em MPa a partir da equação: média das leituras $/ 0,046^{*} 0,098$. Na sequência, as amostras foram secas em estufa a $\pm 105^{\circ} \mathrm{C}$, durante $24 \mathrm{~h}$, visando à determinação da densidade do solo (Blake \& Hartge, 1986).

Foram coletadas amostras indeformadas de solo, na camada de $0-0,10 \mathrm{~m}$, da cultivar CAC- 1 , para obtenção das imagens do sistema radicular, as quais foram digitalizadas em scanner de leitura ótica, na resolução de $400 \mathrm{dpi}$, que forneceram a área $\left(\mathrm{mm}^{2}\right)$, o diâmetro médio $(\mathrm{mm})$ e o comprimento das raízes $(\mathrm{mm})$ pelo software Delta-T Scan, sendo posteriormente determinadas a densidade radicular, a massa seca de raízes e sua densidade.

Após o estádio de maturidade fisiológica dos grãos, em 10 plantas por parcela, foram avaliados a altura das plantas, a altura de inserção da primeira vagem, o peso de 100 grãos e a produtividade, considerando a umidade-padrão de 13\% (Embrapa, 2006).
Os resultados obtidos foram submetidos à análise de variância pelo teste $\mathrm{F}$, e as médias, quando significativas, foram comparadas pelo teste de Tukey a $5 \%$.

\section{RESULTADOS E DISCUSSÃO}

Pode-se observar (Quadro 2) que a macroporosidade $\left(0-0,10 \mathrm{~m}\right.$ ) foi maior no tratamento $\mathrm{C}_{0}$ (sem compactação) em relação aos tratamentos nos quais o solo foi compactado. Contrariamente ao constatado para a macroporosidade, verificou-se menor valor para a microporosidade $(0-0,10 \mathrm{~m})$ no tratamento $\mathrm{C}_{0}$. A movimentação de máquinas e o cultivo do solo provavelmente foram responsáveis por reduzir o volume de macroporos e aumentar o de microporos nos tratamentos com compactação, corroborando os resultados de Niero et al. (2010) em um Latossolo Vermelho distroférrico típico. A microporosidade na camada de 0,10-0,20 m tendeu a reduzir com o aumento do número de passadas do trator.

No tratamento $\mathrm{C}_{6}$ foi verificado, na camada de $0-0,10 \mathrm{~m}$, o menor valor de macroporosidade, porém com menor redução em comparação aos resultados de Freddi et al. (2007), os quais, trabalhando com um Latossolo Vermelho textura média, constataram redução de $80 \%$ no tratamento com seis passadas em relação ao solo não trafegado; contudo, a menor redução na macroporosidade do estudo vigente, provavelmente, está associada à melhor estruturação do solo proporcionada pela textura mais argilosa. Na camada de $0,10-0,20 \mathrm{~m}$, nos tratamentos $\mathrm{C}_{0}=\mathrm{C}_{2}=\mathrm{C}_{4}$, portanto, com seis passadas, ocorreu aumento da macroporosidade, não diferindo da área $\mathrm{C}_{0}$, o que sugere que a escarificação seguida de gradagem tenha favorecido a formação de impedimentos físicos logo abaixo das camadas de solo movimentadas pelos implementos, como verificado por Tavares Filho et al. (2001).

Pagliai et al. (2003) consideram o valor de macroporosidade de $0,10 \mathrm{~m}^{3} \mathrm{~m}^{-3}$ como crítico para o crescimento das plantas; no entanto, pelos resultados obtidos, apenas o solo sem compactação da macroporosidade não tem restrição ao crescimento das plantas, visto que os demais tratamentos, para as duas camadas analisadas, indicam prováveis limitações ao arejamento do solo em épocas mais úmidas, como relatado por Collares et al. (2008). Para solos argilosos, o valor de $0,10 \mathrm{~m}^{3} \mathrm{~m}^{-3}$ de porosidade de aeração já causa inibição ao suprimento adequado de $\mathrm{O}_{2}$ às raízes (Feng et al., 2002).

Quanto à área sem tráfego do trator, a macroporosidade reduziu com a profundidade, provavelmente devido à maior mobilização na camada superior $\mathrm{e}$ 
ao efeito da compressão dos discos da grade na camada de $0,10-0,20 \mathrm{~m}$. Com o aumento do número de passadas do trator sobre o solo preparado, houve redução da macroporosidade na camada superior, e o inverso ocorreu para a microporosidade.

Os valores de densidade do solo apresentados no quadro 2 estão abaixo do preconizado por Camargo \& Alleoni (1997), os quais verificaram que o valor da densidade de $1,55 \mathrm{Mg} \mathrm{m}^{-3}$ é considerado crítico para solos franco-argilosos a argilosos. Observa-se aumento dos valores de densidade do solo (camada de $0-0,10 \mathrm{~m}$ ), bem como diferença estatística dos níveis compactados, em relação ao solo não trafegado, conforme já observado por Bergamin et al. (2010), que, trabalhando com Latossolo Vermelho distroférrico, obtiveram aumento da densidade a partir do tratamento com duas passadas de trator. A tensão feita pelo pneu do trator, provavelmente, não atingiu a subsuperfície $(0,10-0,20 \mathrm{~m})$; assim, o tráfego de trator em até seis passadas não alterou a estrutura do solo, uma vez que o solo nessas condições proporciona maior capacidade de carga. Resultados semelhantes também foram constatados por Bergamin et al. (2010).

A RP, na camada de $0-0,10 \mathrm{~m}$, aumentou com o tráfego do trator, e os tratamentos $\mathrm{C}_{2}, \mathrm{C}_{4}$ e $\mathrm{C}_{6}$ apresentaram os maiores valores, não diferindo entre si (Quadro 2). Por sua vez, Bergamin et al. (2010), trabalhando em Latossolo Vermelho distroférrico muito argiloso, constataram aumento da RP nessa mesma profundidade a partir de quatro passadas do trator, diferindo dos tratamentos com duas e sem tráfego. No nordeste da China, Zhang et al. (2006) verificaram aumento na RP com o tráfego de passadas do trator em até nove vezes com pequenos tratores (massa de $900 \mathrm{~kg}$ ), principalmente até $0,10 \mathrm{~m}$ de profundidade, em um Chernossolo.

No quadro 3 são apresentados os resultados de altura de plantas $(\mathrm{cm})$, altura de inserção da primeira vagem $(\mathrm{cm})$, peso de 100 grãos (g) e produtividade $\left(\mathrm{kg} \mathrm{ha}^{-1}\right)$, obtidos da variedade CAC1 cultivada em diferentes condições (combinação de quatro níveis de compactação do solo e três níveis de irrigação). Para altura de plantas, houve diferença estatística significativa dentro de compactação do solo e irrigação, tendo os níveis menos compactados $\left(\mathrm{C}_{0}\right.$ e $\left.\mathrm{C}_{2}\right)$ e menos irrigados $(0,05$ e 0,01 $\mathrm{MPa}$ ) apresentado maior altura de plantas, o que confirma os resultados mostrados no quadro 2 , correspondente à macroporosidade, onde, nos níveis mais compactados, foram obtidos valores abaixo de $0,10 \mathrm{~m}^{3} \mathrm{~m}^{-3}$; Pagliai et al. (2003) constataram que esse valor é inadequado ao crescimento das plantas. $\mathrm{Na}$ deficiência de aeração nas raízes ocorre redução do crescimento da parte aérea, devido à redução de auxinas, giberelinas e citoquininas e acumulação de etileno e ácido abscísico (Drew, 1983). Taylor \& Brar (1991) relatam que o decréscimo da porosidade e da macroporosidade ocorre em solos compactados com alteração da estrutura, além da baixa disponibilidade de água e nutrientes e da difusão de gases no solo. Já para altura de inserção da primeira vagem, não houve diferença significativa pelo teste $\mathrm{F}$.

Quadro 2. Atributos físicos do Latossolo Vermelho eutroférrico nos quatro níveis de compactação testados

\begin{tabular}{|c|c|c|c|c|}
\hline \multirow{2}{*}{ Camada } & \multicolumn{4}{|c|}{ Nível de compactação } \\
\hline & $\mathrm{C}_{0}(2)$ & $\mathrm{C}_{2}$ & $\mathrm{C}_{4}$ & $\mathrm{C}_{6}$ \\
\hline $\mathrm{m}$ & \multicolumn{4}{|c|}{ Macroporosidade $\left(\mathrm{m}^{3} \mathrm{~m}^{-3}\right)$} \\
\hline $0-0,10$ & $0,142 \mathrm{Aa}^{(1)}$ & $0,077 \mathrm{Ba}$ & $0,059 \mathrm{Cb}$ & $0,015 \mathrm{Db}$ \\
\hline $0,10-0,20$ & $0,079 \mathrm{ABb}$ & $0,066 \mathrm{Ba}$ & $0,076 \mathrm{Ba}$ & $0,092 \mathrm{Aa}$ \\
\hline \multirow[t]{2}{*}{ CV (\%) Parcela } & 8,59 & CV (\%) Subparcela & 15,89 & \\
\hline & \multicolumn{4}{|c|}{ Microporosidade $\left(\mathrm{m}^{3} \mathrm{~m}^{-3}\right)$} \\
\hline $0-0,10$ & $0,391 \mathrm{Bb}$ & $0,419 \mathrm{Aa}$ & $0,422 \mathrm{Aa}$ & $0,424 \mathrm{Aa}$ \\
\hline $0,10-0,20$ & $0,422 \mathrm{Aa}$ & $0,413 \mathrm{ABa}$ & $0,402 \mathrm{Cb}$ & $0,408 \mathrm{BCb}$ \\
\hline \multirow[t]{2}{*}{ CV (\%) Parcela } & 1,78 & CV (\%) Subparcela & 1,60 & \\
\hline & \multicolumn{4}{|c|}{ Densidade do solo $\left(\mathrm{Mg} \mathrm{m}^{-3}\right)$} \\
\hline $0-0,10$ & $1,199 \mathrm{Bb}$ & $1,338 \mathrm{Aa}$ & $1,358 \mathrm{Aa}$ & $1,357 \mathrm{Aa}$ \\
\hline $0,10-0,20$ & $1,318 \mathrm{Ba}$ & $1,367 \mathrm{Aa}$ & $1,368 \mathrm{Aa}$ & $1,329 \mathrm{Ba}$ \\
\hline \multirow{2}{*}{ CV (\%) Parcela } & 1,37 & CV (\%) Subparcela & 2,00 & \\
\hline & \multicolumn{4}{|c|}{ Resistência do solo à penetração (MPa) } \\
\hline $0-0,10$ & $0,707 \mathrm{Bb}$ & $1,489 \mathrm{Aa}$ & $1,884 \mathrm{Aa}$ & $1,569 \mathrm{Aa}$ \\
\hline $0,10-0,20$ & $1,243 \mathrm{Ba}$ & $1,606 \mathrm{ABa}$ & $1,862 \mathrm{Aa}$ & $1,659 \mathrm{ABa}$ \\
\hline CV (\%) Parcela & 24,12 & CV (\%) Subparcela & 13,98 & \\
\hline
\end{tabular}

(1) Médias seguidas da mesma letra maiúscula, na linha, e minúscula, na coluna, não diferem pelo teste de Tukey (p<0,05). ${ }^{(2)} \mathrm{C}_{0}$ : solo não trafegado; $\mathrm{C}_{2}$ : duas passadas; $\mathrm{C}_{4}$ : quatro passadas e $\mathrm{C}_{6}$ : seis passadas de trator de $11 \mathrm{Mg}$. 
Quadro 3. Altura de plantas, altura de inserção da primeira vagem, peso de 100 grãos e produtividade da soja, variedade CAC-1, em um Latossolo Vermelho eutroférrico em função dos tratamentos aplicados

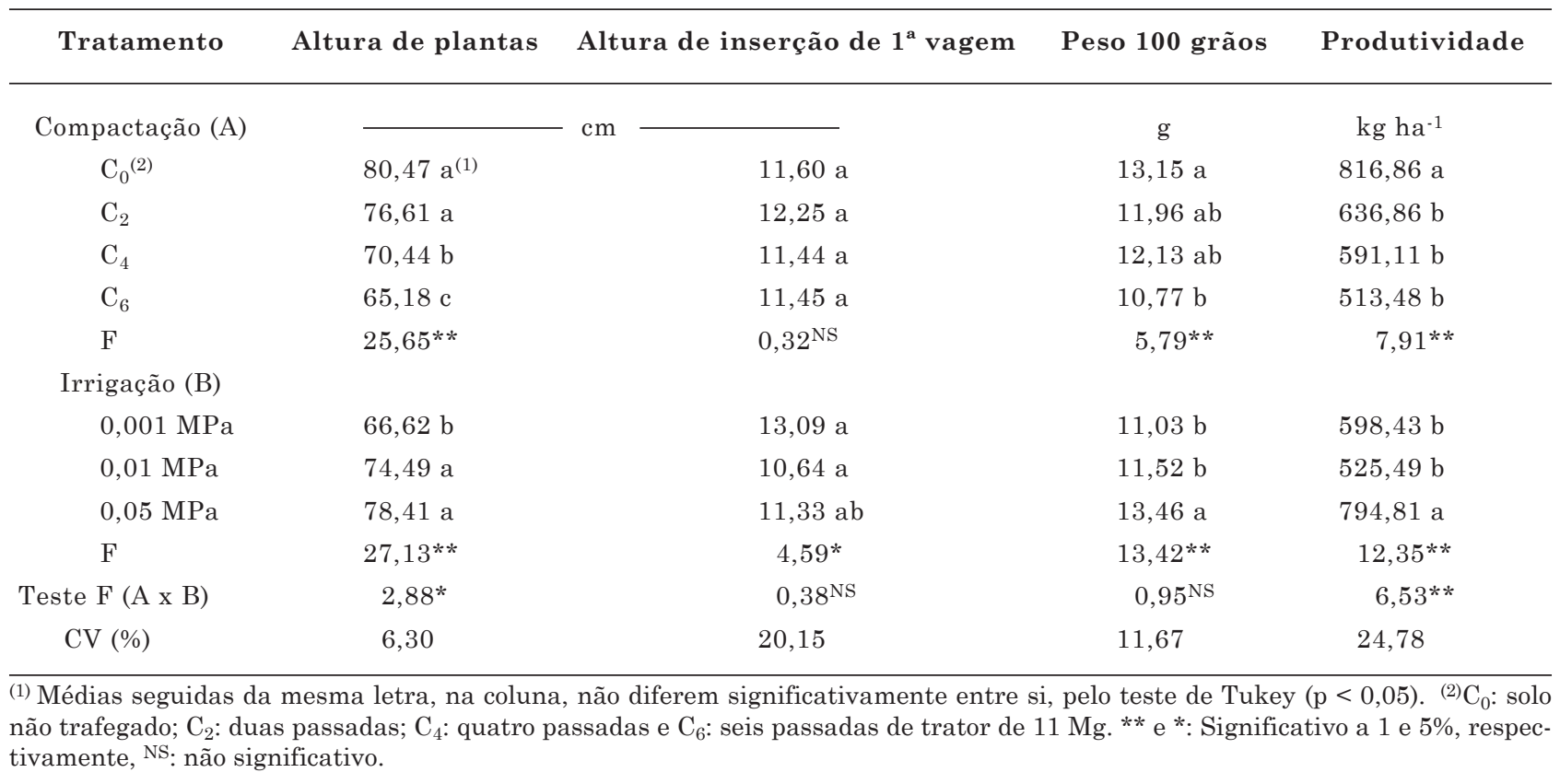

Quanto ao peso de 100 grãos (Quadro 3), o maior valor obtido foi na irrigação de 0,05 $\mathrm{MPa}$, e a compactação $\mathrm{C}_{0}$ diferiu estatisticamente da $\mathrm{C}_{6}$, cujo valor foi inferior. A produtividade foi maior no tratamento menos compactado e no menos irrigado, provavelmente pela melhor estrutura do solo. A melhor distribuição do sistema radicular pode estar relacionada à maior porosidade total e menor impedimento mecânico ao desenvolvimento radicular e, sobretudo, à maior produtividade. Segundo Stirzaker et al. (1996) e Ribeiro (1999), a tolerância das plantas à compactação do solo está diretamente relacionada ao teor de água do solo; assim, esses autores constataram que o valor de resistência que impediu o crescimento radicular é superior em maiores teores de água em relação a solos mais secos e verificaram que em solos com menor teor de água o crescimento de cevada foi superior no menor nível de compactação.

De acordo com os resultados, os níveis maiores de compactação alteraram a produtividade. Segundo Benghough \& Mullins (1990), o menor crescimento radicular em solos compactados ocorre por causa da menor taxa de elongação celular, em razão da diminuição na taxa de divisão celular do meristema.

$\mathrm{Na}$ interação compactação dentro de irrigação (Quadro 4) obteve-se maior altura de plantas entre os níveis menos compactados e menos irrigados; entretanto, na compactação $\mathrm{C}_{2}$ com o maior nível de irrigação, 0,001 MPa, observou-se altura de plantas semelhante a $\mathrm{C}_{4}$ e $\mathrm{C}_{6}$, com maiores níveis de compactação. Assim, de acordo com Camargo \& Alleoni (2011), em condições de solo saturado a compactação diminui a quantidade de água retida pelo solo, porém as baixas tensões em solo compactado retêm menos água do que em um não compactado. Para esses autores, como a compactação diminui a quantidade de poros grandes, ela tem grande influência na transmissão da água em um solo saturado.

No maior nível de irrigação (0,001 MPa) e no menor nível de compactação $\left(\mathrm{C}_{0}\right)$ obteve-se maior produtividade, os quais diferiram estatisticamente dos demais níveis de compactação e de irrigação (Quadro 4). Avaliando o menor nível de irrigação (0,05 $\mathrm{MPa})$, a compactação $\mathrm{C}_{2}$ apresentou elevada produtividade, e esta diferiu da dos demais níveis de irrigação e da compactação $\mathrm{C}_{6}$. Beutler et al. (2007) constataram maior produtividade de soja no cultivo irrigado comparado ao cultivo de sequeiro, na compactação de quatro e seis passadas de um trator de $11 \mathrm{Mg}$, trabalhando com o mesmo solo em estudo.

A produtividade de soja foi aquém do esperado (3,0 a $\left.3,5 \mathrm{t} \mathrm{ha}^{-1}\right)$. Isso provavelmente ocorreu porque o período de dezembro/2009 a abril/2010 foi bastante chuvoso, com o registro de precipitações pluviais de 1.053,6 mm, com a ocorrência de vários dias nublados, que, associados com a semeadura tardia (dezembro) e a ocorrência de níveis altos da ferrugem asiática, apesar do controle químico efetuado, provavelmente, foram os responsáveis pela baixa produtividade. 
Quadro 4. Altura de plantas e produtividade da variedade CAC-1, na interação de compactação dentro de irrigação

\begin{tabular}{|c|c|c|c|c|}
\hline \multirow{2}{*}{ Compactação (A) } & \multicolumn{3}{|c|}{ Irrigação (B) } & \multirow{2}{*}{ F } \\
\hline & $0,001 \mathrm{MPa}$ & $0,01 \mathrm{MPa}$ & $0,05 \mathrm{MPa}$ & \\
\hline \multicolumn{5}{|c|}{ Altura } \\
\hline $\mathrm{C}_{0}{ }^{(2)}$ & $74,55 \mathrm{Ab}^{(1)}$ & $83,00 \mathrm{Aa}$ & $83,85 \mathrm{Aa}$ & $4,97^{*}$ \\
\hline $\mathrm{C}_{2}$ & $63,98 \mathrm{Bb}$ & $81,98 \mathrm{Aa}$ & $83,88 \mathrm{Aa}$ & $22,68^{* *}$ \\
\hline $\mathrm{C}_{4}$ & $66,50 \mathrm{ABb}$ & $68,88 \mathrm{Bab}$ & $75,95 \mathrm{ABa}$ & $4,54^{*}$ \\
\hline $\mathrm{C}_{6}$ & $61,45 \mathrm{Bb}$ & $64,10 \mathrm{Bab}$ & $69,98 \mathrm{Ba}$ & $3,58^{*}$ \\
\hline $\mathrm{F}$ & $6,06^{* *}$ & $16,79^{* *}$ & $8,57^{*}$ & \\
\hline \multicolumn{5}{|c|}{ Produtividade } \\
\hline $\mathrm{C}_{0}(2)$ & $1060,01 \mathrm{Aa}^{(1)}$ & $675,28 \mathrm{Ab}$ & $715,29 \mathrm{ABb}$ & $7,12^{* *}$ \\
\hline $\mathrm{C}_{2}$ & 495,30 Bb & $420,19 \mathrm{Ab}$ & $995,08 \mathrm{Aa}$ & $15,55^{* *}$ \\
\hline $\mathrm{C}_{4}$ & $449,58 \mathrm{Bb}$ & $496,82 \mathrm{Ab}$ & $826,94 \mathrm{ABa}$ & $6,73^{* *}$ \\
\hline $\mathrm{C}_{6}$ & $388,84 \mathrm{Ba}$ & $509,67 \mathrm{Aa}$ & $641,91 \mathrm{Ba}$ & $2,55^{\mathrm{NS}}$ \\
\hline $\mathrm{F}$ & $15,38^{* *}$ & $1,84^{\mathrm{NS}}$ & $3,76^{*}$ & \\
\hline
\end{tabular}

(1)Médias seguidas pela mesma letra maiúscula na coluna e minúscula na linha, não diferem entre si pelo teste de Tukey, a $5 \%$. ${ }^{(2)}$ $\mathrm{C}_{0}$ : solo não trafegado; $\mathrm{C}_{2}$ : duas passadas; $\mathrm{C}_{4}$ : quatro passadas e $\mathrm{C}_{6}$ : seis passadas de trator de $11 \mathrm{Mg}$. ** e *: Significativo a 1 e 5 $\%$, respectivamente, ${ }^{\text {NS: }}$ não significativo.

Com relação a área, comprimento, densidade de comprimento radicular, massa seca e densidade de massa seca radicular $(0-0,10 \mathrm{~m})$, pode-se observar que as compactações e irrigações não interferiram nesses fatores (Quadro 5). O diâmetro radicular foi maior no nível de compactação do solo $\mathrm{C}_{4}$, o qual diferiu significativamente da menor compactação $\left(\mathrm{C}_{0}\right)$; os níveis $\mathrm{C}_{2}$ e $\mathrm{C}_{6}$ não apresentaram efeitos dos tratamentos. No nível de irrigação de $0,001 \mathrm{MPa}$ o diâmetro radicular diferiu significativamente do menor nível de irrigação $(0,05 \mathrm{MPa})$, e o nível de 0,01 MPa não apresentou efeitos dos tratamentos.

Não houve diferença estatística entre as camadas de $0-0,10$ e 0,10-0,20 m (Quadro 6) para a variável diâmetro radicular. Resultados semelhantes foram encontrados por Freddi et al. (2009), que, trabalhando com o mesmo solo em estudo, com a cultura do milho, encontraram menor diâmetro radicular apenas na camada de $0-0,05 \mathrm{~m}$, não havendo diferença estatística entre as camadas $(0,05-0,10,0,10-0,15$ e $0,15-0,20 \mathrm{~m})$.

Os resultados de imagens do sistema radicular coletadas na profundidade de $0,10-0,20 \mathrm{~m}$ estão apresentados no quadro 6. Não houve diferença estatística significativa entre as diferentes intensidades de compactação para os fatores radiculares avaliados: área, comprimento e densidade de comprimento radicular. $\mathrm{O}$ diâmetro, a massa seca e a densidade de massa seca de raiz foram maiores no nível $\mathrm{C}_{4}$ de compactação do solo, diferindo significativamente do menos compactado
$\left(\mathrm{C}_{0}\right)$, e os níveis $\mathrm{C}_{2}$ e $\mathrm{C}_{6}$ não apresentaram efeitos dos tratamentos. Em estudo realizado com raízes de milho, verificou-se maior superfície, densidade e diâmetro radicular, assim como aumento da massa seca, com a elevação da resistência mecânica à penetração do solo, os quais restringiram o crescimento radicular em profundidade (Freddi, 2007).

Dentro dos três níveis de irrigação, bem como na interação compactação x irrigação, não houve diferença estatística para todas as variáveis do sistema radicular da soja. Isso ocorreu porque o período de coleta das raízes de soja - dezembro/2009 a abril/2010 - foi bastante chuvoso, o que provocou alteração entre os níveis de irrigação.

Verificou-se, para a massa seca das raízes, que os menores valores foram obtidos na camada de 0,10-0,20 m (Quadro 6); resultados semelhantes foram encontrados por Freddi et al. (2009), quando foram efetuadas duas passadas de trator de $11 \mathrm{Mg}$. De acordo com Bassoi et al. (1994), a maior concentração de raízes na superfície e a menor exploração do solo em profundidade prejudicam a absorção de água, pois normalmente raízes mais profundas podem retirar água com maior facilidade do que aquelas próximas à superfície do solo, pelo fato de serem mais jovens, menos comprimidas e, frequentemente, localizadas em solo mais úmido. Os maiores benefícios no aumento da profundidade de subsolagem foram observados em anos de menor precipitação pluvial, em que as raízes penetram a 
Quadro 5. Área, diâmetro, comprimento e densidade de comprimento de raízes, massa seca de raízes e densidade de massa seca de raiz, na camada de $0-0,10 \mathrm{~m}$, da variedade de soja CAC-1 cultivada sob diferentes manejos

\begin{tabular}{|c|c|c|c|c|c|c|}
\hline Tratamento & Área $^{(1)}$ & Diâmetro & Comprimento & $\begin{array}{l}\text { Densidade de } \\
\text { comprimento } \\
\text { radicular }\end{array}$ & Massa seca & $\begin{array}{c}\text { Densidade de } \\
\text { massa seca } \\
\text { de raiz }\end{array}$ \\
\hline Compactação (A) & $\mathrm{mm}^{2}$ & $\mathrm{~mm}$ & $\mathrm{~mm}$ & $\mathrm{~cm} \mathrm{~cm}^{-3}$ & $\mathrm{mg}$ & $\mathrm{mg} \mathrm{cm}^{-3}$ \\
\hline $\mathrm{C}_{0}^{(3)}$ & $973,51 \mathrm{a}^{(2)}$ & $0,33 \mathrm{~b}$ & $294,19 \mathrm{a}$ & $0,66 \mathrm{a}$ & $49,74 \mathrm{a}$ & $0,11 \mathrm{a}$ \\
\hline $\mathrm{C}_{2}$ & $966,54 \mathrm{a}$ & $0,37 \mathrm{ab}$ & $258,61 \mathrm{a}$ & $0,58 \mathrm{a}$ & $50,87 \mathrm{a}$ & $0,11 \mathrm{a}$ \\
\hline $\mathrm{C}_{4}$ & $1040,52 \mathrm{a}$ & $0,39 \mathrm{a}$ & $254,71 \mathrm{a}$ & $0,57 \mathrm{a}$ & $58,78 \mathrm{a}$ & $0,13 \mathrm{a}$ \\
\hline $\mathrm{C}_{6}$ & 884,96 a & $0,35 \mathrm{ab}$ & $247,53 \mathrm{a}$ & $0,55 \mathrm{a}$ & 38,83 a & $0,09 \mathrm{a}$ \\
\hline $\mathrm{F}$ & $0,24^{\mathrm{NS}}$ & $3,33^{*}$ & $0,59^{\mathrm{NS}}$ & $0,60^{\mathrm{NS}}$ & $0,78^{\mathrm{NS}}$ & $0,83^{\mathrm{NS}}$ \\
\hline \multicolumn{7}{|l|}{ Irrigação (B) } \\
\hline 0,001 MPa & $990,94 \mathrm{a}$ & $0,39 \mathrm{a}$ & $250,93 \mathrm{a}$ & $0,56 \mathrm{a}$ & $51,76 \mathrm{a}$ & $0,11 \mathrm{a}$ \\
\hline $0,01 \mathrm{MPa}$ & $1125,61 \mathrm{a}$ & $0,36 \mathrm{ab}$ & $309,17 \mathrm{a}$ & $0,69 \mathrm{a}$ & $58,74 \mathrm{a}$ & $0,13 \mathrm{a}$ \\
\hline $0,05 \mathrm{MPa}$ & $782,58 \mathrm{a}$ & $0,33 \mathrm{~b}$ & $231,18 \mathrm{a}$ & $0,51 \mathrm{a}$ & 38,16 a & $0,08 \mathrm{a}$ \\
\hline $\mathrm{F}$ & $2,33^{\mathrm{NS}}$ & $4,23^{*}$ & $2,99^{\mathrm{NS}}$ & $3,02^{\mathrm{NS}}$ & $1,70^{\mathrm{NS}}$ & $1,64^{\mathrm{NS}}$ \\
\hline Teste $\mathrm{F}(\mathrm{A} \times \mathrm{B})$ & $0,55^{\mathrm{NS}}$ & $1,82^{\mathrm{NS}}$ & $0,52^{\mathrm{NS}}$ & $0,53^{\mathrm{NS}}$ & $0,46^{\mathrm{NS}}$ & $0,50^{\mathrm{NS}}$ \\
\hline CV (\%) & 46,88 & 15,38 & 35,58 & 35,70 & 64,84 & 65,36 \\
\hline
\end{tabular}

(1) Leituras das raízes realizadas em "scanner" Delta T de amostras indeformadas de raízes retiradas de cada parcela próxima a planta de soja com trado de volume $=448,31 \mathrm{~mL}$. ${ }^{(2)}$ Médias seguidas da mesma letra, na coluna, não diferem entre si pelo teste de Tukey, a $5 \%$. ${ }^{(3)} \mathrm{C}_{0}$ : solo não trafegado; $\mathrm{C}_{2}$ : duas passadas; $\mathrm{C}_{4}$ : quatro passadas e $\mathrm{C}_{6}$ : seis passadas de trator de $11 \mathrm{Mg}$. ${ }^{*}$ : Significativo a $5 \%$, NS: não significativo.

Quadro 6. Área, diâmetro, comprimento e densidade de comprimento de raízes, massa seca de raízes e densidade de massa seca de raiz, na camada de 0,10-0,20 m, da variedade de soja CAC-1 cultivada sob diferentes manejos

\begin{tabular}{|c|c|c|c|c|c|c|}
\hline Tratamento & Área $^{(1)}$ & Diâmetro & Comprimento & $\begin{array}{c}\text { Densidade de } \\
\text { comprimento radicular }\end{array}$ & Massa seca & $\begin{array}{c}\text { Densidade de } \\
\text { massa seca } \\
\text { de raiz }\end{array}$ \\
\hline Compactação (A) & $\mathrm{mm}^{2}$ & $\mathrm{~mm}$ & $\mathrm{~mm}$ & $\mathrm{~cm} \mathrm{~cm}^{-3}$ & $\mathrm{mg}$ & $\mathrm{mg} \mathrm{cm}-3$ \\
\hline $\mathrm{C}_{0}{ }^{(3)}$ & $499,00 \mathrm{a}^{(2)}$ & $0,31 \mathrm{~b}$ & $158,21 \mathrm{a}$ & $0,35 \mathrm{a}$ & $21,91 \mathrm{~b}$ & $0,05 \mathrm{~b}$ \\
\hline $\mathrm{C}_{2}$ & $530,22 \mathrm{a}$ & $0,34 \mathrm{ab}$ & $154,80 \mathrm{a}$ & $0,34 \mathrm{a}$ & $29,93 \mathrm{ab}$ & $0,07 \mathrm{ab}$ \\
\hline $\mathrm{C}_{4}$ & 842,87 a & $0,39 \mathrm{a}$ & $205,41 \mathrm{a}$ & $0,46 \mathrm{a}$ & $55,80 \mathrm{a}$ & $0,13 \mathrm{a}$ \\
\hline $\mathrm{C}_{6}$ & $630,43 \mathrm{a}$ & $0,35 \mathrm{ab}$ & $177,42 \mathrm{a}$ & $0,40 \mathrm{a}$ & $36,99 \mathrm{ab}$ & $0,08 \mathrm{ab}$ \\
\hline $\mathrm{F}$ & $2,29^{\mathrm{NS}}$ & $3,03^{*}$ & $0,93^{\mathrm{NS}}$ & $0,93^{\mathrm{NS}}$ & $2,74^{*}$ & $2,87^{*}$ \\
\hline \multicolumn{7}{|l|}{ Irrigação (B) } \\
\hline 0,001 MPa & $585,80 \mathrm{a}$ & $0,34 \mathrm{a}$ & $162,25 \mathrm{a}$ & $0,36 \mathrm{a}$ & $28,25 \mathrm{a}$ & $0,06 \mathrm{a}$ \\
\hline $0,01 \mathrm{MPa}$ & 687,26 a & $0,35 \mathrm{a}$ & $192,62 \mathrm{a}$ & $0,43 \mathrm{a}$ & $39,60 \mathrm{a}$ & $0,09 \mathrm{a}$ \\
\hline $0,05 \mathrm{MPa}$ & 603,83 a & 0,35 a & $167,01 \mathrm{a}$ & $0,37 \mathrm{a}$ & $40,63 \mathrm{a}$ & $0,09 \mathrm{a}$ \\
\hline $\mathrm{F}$ & $0,37^{\mathrm{NS}}$ & $0,11^{\mathrm{NS}}$ & $0,61^{\mathrm{NS}}$ & $0,65^{\mathrm{NS}}$ & $0,82^{\mathrm{NS}}$ & $0,82^{\mathrm{NS}}$ \\
\hline Teste F (A x B) & $0,52^{\mathrm{NS}}$ & $0,67^{\mathrm{NS}}$ & $0,42^{\mathrm{NS}}$ & $0,43^{\mathrm{NS}}$ & $0,34^{\mathrm{NS}}$ & $0,37^{\mathrm{NS}}$ \\
\hline CV (\%) & 56,77 & 18,95 & 48,04 & 48,00 & 83,80 & 83,36 \\
\hline
\end{tabular}

(1) Leituras das raízes realizadas em "scanner" Delta $\mathrm{T}$ de amostras indeformadas de raízes retiradas de cada parcela próxima a planta de soja com trado de volume $=448,31 \mathrm{~mL}$. ${ }^{(2)}$ Médias seguidas da mesma letra, na coluna, não diferem entre si pelo teste de Tukey, a $5 \%$. ${ }^{(3)} \mathrm{C}_{0}$ : solo não trafegado; $\mathrm{C}_{2}$ : duas passadas; $\mathrm{C}_{4}$ : quatro passadas e $\mathrm{C}_{6}$ : seis passadas de trator de $11 \mathrm{Mg}$. *: Significativo a $5 \%$, NS: não significativo.

maiores profundidades, explorando maior volume de solo, e extraem mais água e nutrientes, reduzindo as condições desfavoráveis para o desenvolvimento da cultura, o que resulta em maiores produtividades (Varsa et al., 1997).
Pela matriz de correlação da variedade de soja CAC-1 (Quadro 7), verifica-se que todas as características do sistema radicular avaliadas na camada de $0-0,10 \mathrm{~m}$ correlacionaram-se diretamente. A produtividade da soja correlacionou- 
Quadro 7. Matriz de correlações entre os coeficientes da área (A), diâmetro (D), comprimento (C), densidade de comprimento de raízes (Ds), massa seca de raízes (Ms), densidade de massa seca de raiz (DMs) e produtividade (Prod) da variedade de soja CAC-1 submetida a diferentes intensidades de compactação

\begin{tabular}{ccccccc}
\hline Característica & $\mathrm{A}$ & $\mathrm{D}$ & $\mathrm{C}$ & $\mathrm{Ds}$ & $\mathrm{Ms}$ & $\mathrm{DMs}$ \\
\hline $\mathrm{D}$ & $0,67^{* *}$ & - & - & - & - & - \\
$\mathrm{C}$ & $0,90^{* *}$ & $0,30^{*}$ & - & - & - & - \\
Ds & $0,90^{* *}$ & $0,30^{*}$ & $1,00^{* *}$ & - & - & - \\
MS & $0,91^{* *}$ & $0,70^{* *}$ & $0,77^{* *}$ & $0,77^{* *}$ & - & - \\
DMs & $0,92^{* *}$ & $0,70^{* *}$ & $0,77^{* *}$ & $0,78^{* *}$ & $1,00^{* *}$ & - \\
Prod & $-0,07^{\mathrm{NS}}$ & $-0,23^{\mathrm{NS}}$ & $0,03^{\mathrm{NS}}$ & $0,03^{\mathrm{NS}}$ & $-0,05^{\mathrm{NS}}$ & $-0,05^{\mathrm{NS}}$ \\
\hline
\end{tabular}

** e *: Significativo a 1 e $5 \%$, respectivamente, ${ }^{\text {NS}}$ : não significativo.

se diretamente apenas com o comprimento de raízes e a densidade de comprimento de raízes, porém não foram significativos. Isso corrobora os resultados de Freddi et al. (2009), em cujo trabalho com a cultura do milho encontrou correlação significativa da produtividade apenas com o diâmetro radicular; segundo esses autores, a variabilidade espacial e temporal da estrutura do solo é um dos fatores que dificultam quantificar as propriedades físicas do solo, pois estas variam conjuntamente. A influência da compactação do solo sobre o crescimento radicular depende de uma série de fatores, entre os quais as características genéticas das plantas e o seu estádio de desenvolvimento, bem como das condições ambientais (Bennie, 1996).

Quando o solo estava pouco compactado, o déficit hídrico proporcionou produtividade superior; esse fato ocorreu devido à melhor distribuição do sistema radicular da soja, segundo Cardoso et al. (2006). Para Kooistra et al. (1992), um solo com pequena compactação apresenta benefícios por aumentar a área de contato solo/raiz, proporcionando adequado suprimento de água e nutrientes à parte aérea.

A resistência do solo à penetração de 1,66 $\mathrm{MPa}$ na tensão de $50 \mathrm{kPa}$ mostrou redução da produtividade. Para Reichert et al. (2007), também em um Latossolo Vermelho eutroférrico típico textura argilosa, uma resistência de 3,05 e $2,81 \mathrm{MPa}$, com teores de água de $0,24 \mathrm{~kg} \mathrm{~kg}^{-1}$ (tensão de $50 \mathrm{kPa}$ ), reduziu a produtividade da cultura da soja. Em solos com elevada $R P$, há redução da profundidade do sistema radicular da soja, na qual ocorre menor conteúdo de água e, consequentemente, menor absorção de água e nutrientes, refletindo em decréscimo de produtividade (Cardoso et al., 2006), devido ao aumento da produção e concentração de ácido abscísico nas raízes e envio à parte aérea, induzindo a planta a diminuir seu crescimento (Mulholland et al., 1996).

\section{CONCLUSÕES}

1. O desenvolvimento da planta foi influenciado pela compactação do solo e pelos conteúdos de água no solo. Níveis mais altos de compactação e de água no solo provocaram redução da altura de plantas e da produtividade. A produtividade máxima da soja foi obtida com a resistência do solo à penetração de $0,71 \mathrm{MPa}$.

2. O diâmetro radicular foi maior na compactação $\mathrm{C}_{4}$, nas duas profundidades; entretanto, com aumento da compactação, consequentemente, há aumento do diâmetro, o que inibe o desenvolvimento do sistema radicular em solos compactados. O sistema radicular correlacionou-se inversamente com a produtividade da soja.

\section{LITERATURA CITADA}

AGRIANUAL 2011: Anuário da agricultura brasileira. São Paulo, FNP Consultoria e Comércio, 2011. p.419-450.

ANDRIOLI, I. \& CENTURION, J.F. Levantamento detalhado dos solos da Faculdade de Ciências Agrárias e Veterinárias de Jaboticabal. In: CONGRESSO BRASILEIRO DE CIÊNCIA DO SOLO, 27., Brasília, 1999. Anais... Brasília, Sociedade Brasileira de Ciência do Solo, 1999. p.1-4 CD ROM.

BARBER, R.G. Persistence of loosened horizons and soybean yield increases in Bolivia. Soil Sci. Soc. Am. J., 58:943-950, 1994.

BASSOI, L.H.; FANTE JÚNIOR, L.; JORGE, L.A.C.; CRESTANA, S. \& REICHARDT, K. Distribuição do sistema radicular do milho em terra roxa estrutura latossólica: II. Compactação entre cultura irrigada e fertirrigada. Sci. Agric., 51:541$548,1994$.

BENGOUGH, A.G. \& MULLINS, C.E. Mechanical impedance to root growth: A review of experimental techniques and root growth responses. J. Soil Sci., 41:341-358, 1990. 
BENNIE, A.P.T. Growth and mechanical impedance. In: WAISEL, Y.; ESHEL, A. \& KAFKAFI, U., eds. Plant roots. New York, M. Dekker, 1996. p.453-470.

BERGAMIN, A.C.; VITORINO, A.C.T.; FRANCHINI, J.C.; SOUZA, C.M.A. \& SOUZA, F.R. Compactação em um Latossolo Vermelho distroférrico e suas relações com o crescimento radicular do milho. R. Bras. Ci. Solo, 34:681$691,2010$.

BEUTLER, A.N. \& CENTURION, J.F. Compactação do solo no desenvolvimento radicular e na produtividade da soja. Pesq. Agropec. Bras., 39:581-588, 2004.

BEUTLER, A.N.; CENTURION, J.F.; CENTURION, M.A.P.C.; LEONEL, C.L.; JOÃO, A.C.G.S. \& FREDDI, O.S. Intervalo hídrico ótimo no monitoramento da compactação e da qualidade física de um Latossolo Vermelho cultivado com soja. R. Bras. Ci. Solo, 31:1223-1232, 2007.

BEUTLER, S.J.; LOSS, A.; PEREIRA, M.G.; ANJOS, L.H.C.; FERREIRA, E.P.; SANTOS, L.L. \& SILVA, E.M.R. Frações oxidáveis do carbono orgânico cultivado sob manejo orgânico. In: FERTBIO, 2008. Desafios para o uso do solo com eficiência e qualidade ambiental. Londrina, 2008. Anais... Londrina, 2008. CD ROM.

BLAKE, G.R. \& HARTGE, K.H. Bulk density. In: KLUTE, A., ed. Methods of soil analysis. 2.ed. Madison, America Society of Agronomy, 1986. p.363-375.

CAMARGO, O.A. \& ALLEONI, L.R.F. Efeitos da compactação em atributos do solo. 2006. Artigo em Hypertexto. Disponível em: <http://www.infobibos.com/Artigos/CompSolo/C4/ Comp4.htm>. Acesso em: 20 de out. de 2011.

CAMARGO, O.A. \& ALLEONI, L.R.F. Compactação do solo e o desenvolvimento das plantas. Piracicaba, Escola Superior de Agricultura Luiz de Queiroz, 1997. 132p.

CARDOSO, E.G.; ZOTARELLI, L.; PICCININ, J.L.; TORRES, E.; SARAIVA, O.F. \& GUIMARÃES, M.F. Sistema radicular da soja em função da compactação do solo no sistema plantio direto. Pesq. Agropec. Bras., 41:493-501, 2006.

CENTURION, J.F. Caracterização e classificação dos solos da Faculdade de Ciências Agrárias e Veterinárias de Jaboticabal. Jaboticabal, Universidade Estadual Paulista "Júlio de Mesquita Filho", 1998. 84p. (Tese de Livre Docência)

COLLARES, G.L.; REINERT, D.J.; REICHERT, J.M. \& KAISER, D.R. Compactação de um Latossolo induzida pelo tráfego de máquinas e sua relação com o crescimento e produtividade de feijão e trigo. R. Bras. Ci. Solo, 32:933-942, 2008.

DANIELSON, R.E. \& SUTHERLAND, P.L. Porosity. In: KLUTE, A. ed. Methods of soil analysis: Physical and mineralogical methods. 2.ed. Madison, American Society of Agronomy, 1986. Part 1. p.443-461.

DEXTER, A.R. Mechanics of root growth. Plant Soil, 98:303$312,1987$.
DREW, M.C. Plant injury and adaptation to oxygen deficiency in the root environment. Plant Soil, 75:179-199, 1983.

EMPRESA BRASILEIRA DE PESQUISA AGROPECUÁRIA - EMBRAPA. Tecnologia de produção de soja: Região Central do Brasil 2007. Londrina, 2006. 225p. (Sistemas de Produção, 11)

FENG, G.; WU, L. \& LETEY, J. Evaluating aeration criteria by simultaneous measurement of oxygen diffusion rate and soil-water regime. Soil Sci., 167:495-503, 2002.

FREDDI, O.S. Avaliação do intervalo hídrico ótimo em Latossolo Vermelho cultivado com milho. Jaboticabal, Faculdade de Ciências Agrárias e Veterinárias, 2007. 105p. (Tese de Doutorado)

FREDDI, O.S.; CENTURION; J.F.; BEUTLER, A.N.; ARATANI, R.G. \& LEONEL, C.L. Compactação do solo no crescimento radicular e produtividade da cultura do milho. R. Bras. Ci. Solo, 31:627-636, 2007.

FREDDI, O.S.; CENTURION, J.F.; DUARTE, A.P. \& LEONEL, C.L. Compactação do solo e produção de cultivares de milho em Latossolo Vermelho. I - Características de planta, solo e índice S. R. Bras. Ci. Solo, 33:793-803, 2009.

GEE, G.W. \& BAUDER, J.W. Particle-size analysis. In: KLUTE, A., ed. Methods of soil analysis. 2.ed. Madison, American Society of Agronomy, 1986. Part 1. p.383-411.

KIEHL, E.J. Manual de edafologia. São Paulo, Agronômica Ceres, 1979. 262p.

KLUTE, A. Water retention: Laboratory methods. In: KLUTE, A., ed. Methods of soil analysis. 2.ed. Madison, American Society of Agronomy, 1986. p.635-660.

KOOISTRA, M.J.; SCHOONDERBEEK, D.; BOONE, F.R.; VEEN, B.W. \& NOORDWIJK, M. van. Root-soil contact of maize, as measured by a thin-section technique. II. Effects of soil compaction. Plant Soil, 139:119-129, 1992.

LETEY, J. Relationship between soil physical properties and crop production. Adv. Soil Sci., 1:277-294, 1985.

LIPIEC, J.; ISHIOKA, T.; HATANO, R. \& SAKUMA, T. Effects of soil structural discontinuity on root and shoot growth and water use of maize. Plant Soil, 157:65-74, 1993.

MULHOLLAND, B.J.; BLACK, C.R.; TAYLOR, I.B.; ROBERTS, J.A. \& LENTON, J.R. Effect of soil compaction on barley (Hordeum vulgare L.) growth. I. Possible role for ABA as a root-sourced chemical signal. J. Exper. Bot., 47:539-549, 1996.

NIERO, L.A.C.; DECHEN, S.C.F.; COELHO, R.M. \& DE MARIA, I.C. Avaliações visuais como índice de qualidade do solo e sua validação por análises físicas e químicas em um Latossolo Vermelho distroférrico com usos e manejos distintos. R. Bras.Ci. Solo, 34:1271-1282, 2010.

PAGLIAI, M.; MARSILI, A.; SERVADIO, P.; VIGNOZZI, N. \& PELLEGRINI, S. Changes in some physical properties of a clay soil in Central Italy following the passage of rubber tracked and wheeled tractors of médium power. Soil Till. Res., 73:119-129, 2003. 
RAIJ, B.van; CANTARELLA, H.; QUAGGIO, J.H. \& FURLANI, A.M.C. Recomendação de adubação e calagem para o Estado de São Paulo. 2.ed. Campinas, Instituto Agronômico \& Fundação IAC, 1996. 285p. (Boletim Técnico, 100)

REICHERT, J.M.; SUZUKI, L.E.A.S. \& REINERT, D.J. Compactação do solo em sistemas agropecuários e florestais: Identificação, efeitos, limites críticos e mitigação. In: CERRETA, C.A.; SILVA, L.S. \& REICHERT, J.M. Tópicos em ciência do solo. 5.ed. Viçosa, MG, Sociedade Brasileira de Ciência do Solo, 2007. v.5. p.49-134.

RIBEIRO, M.A.V. Resposta da soja e do eucalipto a fósforo em solos de diferentes texturas, níveis de densidade e de umidade. Lavras, Universidade Federal de Lavras, 1999. 71p. (Tese de Doutorado)

SILVA, M.A.S.; MAFRA, Á.L.; ALBUQUERQUE, J.A.; ROSA, J.D.; BAYER, C. \& MIELNICZUK, J. Propriedades físicas e teor de carbono orgânico de um Argissolo Vermelho sob distintos sistemas de uso e manejo. R. Bras. Ci. Solo, 30:329-337, 2006.

SILVA, V.R.; REINERT, D.J. \& REICHERT, J.M. Resistência mecânica do solo à penetração influenciada pelo tráfego de uma colhedora em dois sistemas de manejo do solo. Ci. Rural, 30:795-801, 2000.

STIRZAKER, R.J.; PASSIOURA, J.B. \& WILMS, Y. Soil structure and plant growth: Impact of bulk density and biopores. Plant Soil, 185:151-162, 1996.

STONE, L.F.; GUIMARÃES, C.M. \& MOREIRA, J.A.A. Compactação do solo na cultura do feijoeiro. I: Efeitos nas propriedades físico-hídricas do solo. R. Bras. Eng. Agric. Amb., 6:207-212, 2002.
TAVARES FILHO, J.; BARBOSA, G.M.; GUIMARÃES, M.F. \& FONSECA, I.C.B. Resistência à penetração e desenvolvimento do sistema radicular do milho (Zea mays) sob diferentes sistemas de manejo em um Latossolo Roxo. R. Bras. Ci. Solo, 25:725-730, 2001.

TAYLOR, H.M. \& BRAR, G.S. Effect of soil compaction on root development. Soil Till. Res., 19:111-119, 1991.

TORMENA, C.A.; SILVA, A.P. \& LIBARDI, P. Caracterização do intervalo hídrico ótimo de um Latossolo Roxo sob plantio direto. R. Bras. Ci. Solo, 22:573-581, 1998.

TURNER, N.C. Further progress in crop water relations. Adv. Agr., 58:293-325, 1997.

VARQUEZ, L.; MYHRE, D.L.; GALLAHER, R.N.; HANLON, E.A. \& PORTIER, K.M. Soil compaction associated with tillage treatments for soybean. Soil Till. Res., 13:35-45, 1989.

VARSA, E.C.; CHONG, S.K.; ABOLAJI, J.O.; FARQUHAR, D.A. \& OLSEN, F.J. Effect of deep tillage on soil physical characteristics and corn (Zea mays L.) root growth and production. Soil Till. Res., 43:219-228, 1997.

ZHANG, X.Y.; CRUSE, R.M.; SUI, Y.Y. \& JHAO, Z. Soil compaction induced by small tractor traffic in Northeast China. Soil Sci. Soc. Am. J., 70:613-619, 2006. 
